\title{
THE MARGINAL FIT AND FRACTURE RESISTANCE OF FOUR-UNIT MONOLITHIC AND BI -LAYERED ZIRCON FIXED DENTAL PROSTHESIS
}

\author{
Amany M. Korsel*
}

\begin{abstract}
Purpose: This study aimed to evaluate the fit and fracture resistance of monolithic and Bi -layered zircon fixed dental prosthesis.

Materials and Methods:20 master models composed of two metal abutments and embedded vertically in autopolymerizing acrylic resin blocks to mimic clinical conditions for a four-unit FDPs. Twenty FDPs were fabricated and divided into two groups $(\mathrm{n}=10)$ : group A, bilayered zirconia four-unit FDPs; group B, monolithic zirconia four-unit FDPs. The marginal gap of each retainer specimens was measured for both groups at 18 sites on the margin of the master dies using a digital microscope. Paired t-test was used to evaluate mean marginal gap changes. One-way ANOVA and post hoc tests were also employed for comparison among 2 groups $(\alpha=.05)$. the Samples in each group were cemented to their corresponding model and then underwent artificial ageing by thermocycling of 5000/cycle. The fracture resistance test was done using universal testing machine at cross-head speed of $1 \mathrm{~mm} / \mathrm{min}$. Statistical analysis of the results and comparison between each two groups were performed using independent $\mathrm{t}$,test (significance: $\mathrm{P} \leq 0.05$ ).
\end{abstract}

Results: Marginal gap was increased after porcelain veneering. The mean marginal gap values after veneering in the layering group $(52.06 \mu \mathrm{m})$ was higher monolithic group $(21.4 \mu \mathrm{m})$ in molar die margin CONCLUSION Three veneering methods altered the marginal fit of zirconia copings. All ceramic crowns made through two methods revealed clinically acceptable marginal fit.

KEYWORDS: Marginal fit, CAD/CAM, Zirconia, Layering,

\section{INTRODUCTION}

Recently, the use of computer-aided design/ computer-aided manufacturing (CAD/CAM) systems in fabrication of all ceramic restorations has been improved rapidly ${ }^{[1]}$. This new technology is aimed to produce restorations with higher mechanical properties compared to conventional methods generating new materials and systems for fabrication of dental restorations ${ }^{[2,3]}$. Yttriastabilized tetragonal zirconia polycrystalline (Y-TZP) is commonly used for fabrication of all

\footnotetext{
* Ass,Prof, Fixed Prosthodontics Department, Faculty of Dentistry, Tanta University, Egypt.
} 
ceramic frameworks by means of CAD/CAM due to its unique characteristics including excellent biocompatibility, low plaque accumulation and unsurpassed mechanical properties ${ }^{[4]}$.

Additionally marginal fit is one of the fundamental requirements for clinical success and durability of dental restorations ${ }^{[5]}$. Inaccurate marginal accuracy lead to a leakage between restoration and prepared tooth, that lead to the dissolution of luting agent ${ }^{[6]}$. Subsequently, oral bacteria and food debris accumulate in this space, causing secondary caries, pulpal lesions, postoperative sensitivity, in case of tooth supported restoration and periodontal disease and marginal discoloration impaired bone-implant interface in case of implant supported ones ${ }^{[7-10]}$.

The maximum acceptable marginal opening is $120 \mu \mathrm{m}$ according to some studies ${ }^{[1]]}$.In CAD/CAM restorations, it is supposed that due to the reduction in many manual procedures errors and material imperfections, the less acceptable marginal gap was less than $100 \mu \mathrm{m}^{[12]}$.

Marginal fit of the crown is assessed by measuring the gap between the abutment and inner surface of the restoration. The measurement of the marginal gap in the path of insertion and removal of the restoration is named as vertical marginal discrepancy ${ }^{[13,14]}$. Several techniques have been used for measuring the marginal fit of restorations including direct microscopic view, cross-sectional view,replica technique, laser videography, and x-ray microtomography ${ }^{[15-18]}$. As the direct measuring is a nondestructive technique, it is a proper method for evaluation of the marginal adaptaion during producing procedures of the restorations ${ }^{[15]}$.

Zirconia frameworks are usually veneered using the conventional layering technique. In recent years, some new veneering techniques have been introduced, aiming to reproduce stronger veneers to reduce debonding and chipping of zirconia veneers. Monolithic technique have shown higher mechanical properties compared to layering technique ${ }^{[19-22]}$.
Pak et al. ${ }^{[26]}$ reported that veneering process increased the marginal gap of the final restoration pointed out larger marginal gap on the facial and lingual sides of the specimens, which was directly related to the amount of veneering porcelain ${ }^{[27-29]}$. In another study performed by Cho et al. ${ }^{[30]}$ the marginal gap increased for two pressable ceramic systems (Esthetic and IPS e.max Press) during veneer application. Although, they found the reduction of marginal gap in the characterization and glazing firing cycle. In contrast to these findings, Miura et al. ${ }^{[31]}$ reported marginal stability .

This study provided comparison regarding the effect of veneering technique versus monolithic restoration on the marginal adaptation of zirconia coping. The null hypothesis was that the differences would be found in the marginal fit of monolithic zirconia CAD/CAM crowns and veneered zirconia coping.

\section{MATERIALS AND METHODS}

\section{Fabrication of master model}

20 master models composed of two metal abutments (first lower premolar and second molar)their corresponding to prepared teeth with shoulder $1.0 \mathrm{~mm}$ finish line embedded vertically in autopolymerizing acrylic resin blocks with the aid of surveyor to standardized the parallism of both dies and to mimic clinical conditions for a four-unit FDPs.

\section{Twenty unit FDPs were divided into two groups $(n=10)$}

Group (Monolithic Zirconia FDPs), fabricated by CAD/CAM system was unified to a thickness of $2 \mathrm{~mm}$ at the central fossa, $2.5 \mathrm{~mm}$ at the height of contour and $1 \mathrm{~mm}$ at the cervical margin. The connector's dimensions were $4 \mathrm{~mm}$ occlusogingival height and $4 \mathrm{~mm}$ buccolingual width $\left(4 \times 4 \mathrm{~m}^{2}\right)$.

Group (Double -Layered Zircon FDPs): Ten 
zirconium oxide frameworks were fabricated using CAD/CAM system. Minimum thickness of the frameworks at the occlusal and lateral circumferences was $0.8 \mathrm{~mm}$ and at the cervical margin a thickness of $0.5 \mathrm{~mm}$ was fabricated. Connectors' dimensions were fabricated as the previous ones. The external surface of frameworks were air-abraded with $100 \mu \mathrm{g} \mathrm{Al}_{2} \mathrm{O}_{3}$ at a distance of $10 \mathrm{~mm}$. To standardize veneer application, one sample of monolithic group was chosen and from which a silicone template was prepared.

A silicone index was a guide to establish standardized shape and size of veneers with a homogenous veneering thickness of range between $0.7 \mathrm{~mm}$ at margins and $1.2 \mathrm{~mm}$ at occlusal surfaces. To veneer the copings with layering technique, the liner (IPS e.max, zirliner; Ivoclar Vivadent) was applied to the zirconia copings, and they fired in a compatible ceramic furnace (Programmat 700; Ivoclar Vivadent) at $960^{\circ} \mathrm{C}$; then a nano-fluoroapatite glass ceramic (IPS e.max Ceram; Ivoclar Vivadent) was applied in dentin and enamel layers and processed at $750^{\circ} \mathrm{C}$, followed by glazing and finishing procedures to complete the restorations. The occlusal surface of the crowns was accommodated to the holding device tip to ensure the same seating of them as copings on the metal abutments.

\section{Measuring the leakage}

Each zirconia bridge was seated on the two metal abutments and mounted on a specially holding device. Due to the cone configuration of holding device tip, the samples could seat on the abutments only in one position. A uniform load of $5 \mathrm{~N}$ was applied to all specimens to ensure completely seating. Then the images made from the 14 previously marked points for each abutment along circumferential margin using a digital microscope (AM413FIT Dino-Lite Pro; Dino-Lite electronic corp., Taipei, Taiwan) were connected to a personal computer and photographed at $\times 200$ magnification. These images were then analyzed with image analysis software (Dino Capture 2.0,An Mo Electronics Corp., Tainan Hsien, Taiwan).The vertical marginal gap was evaluated by measuring the perpendicular line from the most cervical external edge of the restoration to the most outer edge of the finish line of the preparation .(Fig. 1)

\section{Fracture Resistance}

20 FDPs were cemented to the abutments with temporary luting cement under a constant load of $30 \mathrm{~N}$ during setting period with a universal testing machine to control cement thickness.

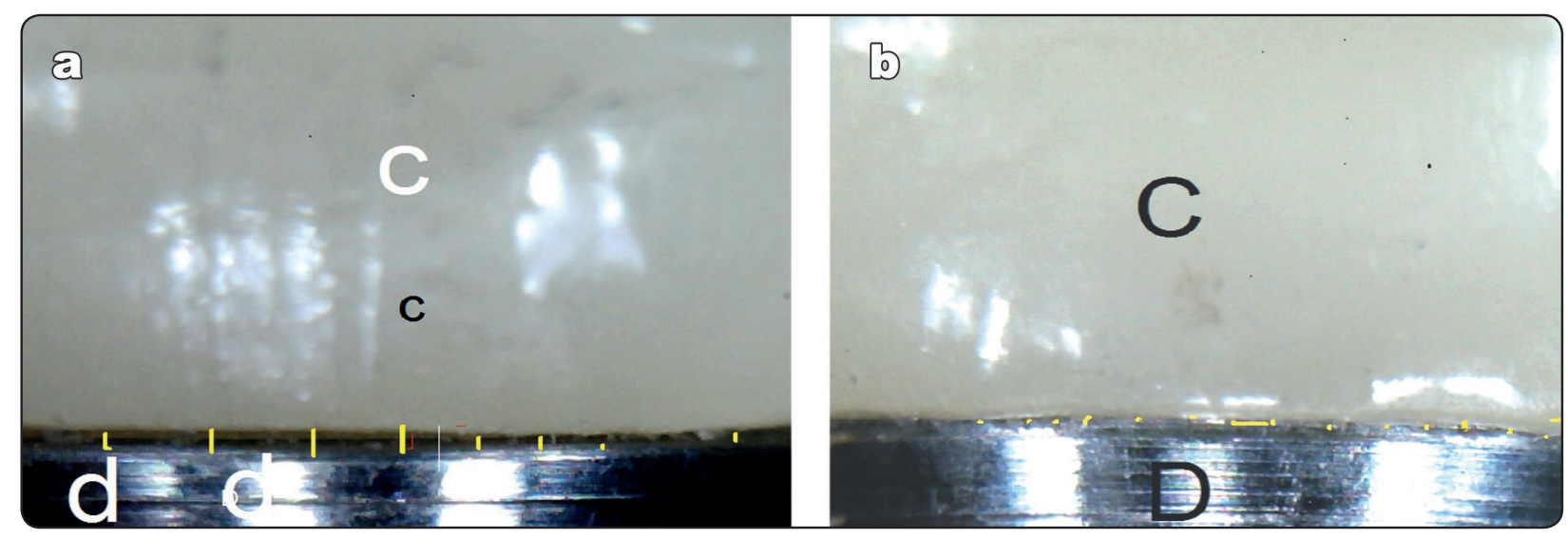

Fig. (1) Microscopic image of coping-die interface at $\times 40$ magnification (zirconia coping (a) monolithic (b) 
All test specimens were exposed to 240,000 cycles of thermo-mechanical fatigue in a computer controlled dual-axis chewing simulator to simulate 12 months of clinical function. Bridge samples were secured to the lower fixed compartment of a universal testing machine and subjected to a vertical compression load. The load was applied occlusally at the connector area between the two pontics using a metallic bar with spherical tip
(6.5 $\mathrm{mm}$ diameter) attached to the upper movable compartment of the universal testing machine and traveling at cross-head speed of $1 \mathrm{~mm} / \mathrm{min}$. Tin foil sheet was placed on the occlusal surface to achieve homogenous distribution of the applied stress. The load at failure was manifested by a crack and confirmed by a sharp drop at load-deflection curve recorded using computer software. The load of the fracture was recorded in Newton (Fig. 2)

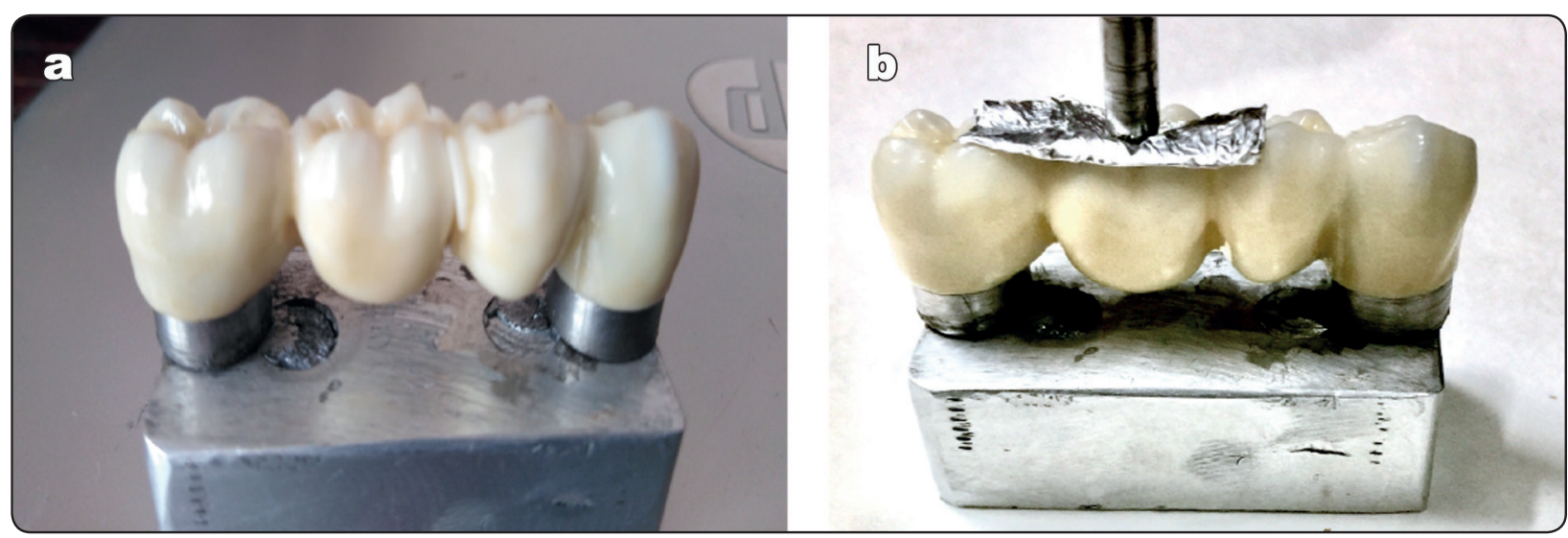

Fig. (2) Fractured four unite bridge

\section{RESULTS}

The means and standard deviations were calculated in each group. Paired t-test was used to compare the marginal gap of monolithic and veneered specimens One-way ANOVA and post hoc tests were used to compare the marginal space. The significance level of $5 \%$ was used for all of the statistical tests

The means and standard deviations for the marginal gap of the specimens in experimental groups are included in Table 1. Statistical analysis revealed no difference between measurements of fit values of two groups with and without veneer (monolithic) $(P \leq 141)$. The vertical marginal gap of the group was increased after porcelain veneering $(P \leq .001)$. The highest mean marginal gap values after veneering was $(48.06 \mu \mathrm{m})$, which was higher than the other $(42.04 \mu \mathrm{m})$. No statistically significant difference was found between the marginal gap values of monolithic and veneered group .

Also the statistical analysis revealed no significant difference between measurements of fit values of two groups monolithic and veneered zircone in premolar retainer margin $(P \leq .124)$. The vertical marginal gap of the group was increased in case of veneered group The highest mean marginal gap values was $(49.1 \mu \mathrm{m})$, which was higher than the monolithic $(40.6 \mu \mathrm{m})$. However there is statistically significant difference between the marginal gap values of monolithic and veneered group in case of molar retainer where marginal gap in veneered gp is $(51.8 \mu \mathrm{m})$ and in monolithic gp is $(25.5 \mu \mathrm{m})$. as in Table 2. 
TABLE (1) Vertical marginal gap measurement of the two groups specimens $(\mu \mathrm{m})$

\begin{tabular}{c|c|c|c|c|c|c|}
\hline Group & $\mathrm{N}$ & Mean & Std. Deviation & Std. Error Mean & $\mathrm{t}$ & $\mathrm{P}$ value \\
\hline Layerd & 65 & 48.4696 & 23.164487 & 2.873201 & 1.480 & .141 \\
monolethic & 66 & 42.0494 & 26.365645 & 3.245387 & & \\
\hline
\end{tabular}

TABLE (2) Mean and SD of marginal gap of molar and premolar circumfrential margin i $\mathrm{n}$ two groups

\begin{tabular}{|c|c|c|c|c|c|c|c|c|}
\hline \multicolumn{2}{|c|}{} & Group & N & Mean & Std. Deviation & $\begin{array}{c}\text { Std. Error } \\
\text { Mean }\end{array}$ & t & P value \\
\hline Premolar & & layerd & 43 & 49.1891 & 23.036119 & 3.512975 & & \\
\hline \multirow{2}{*}{$\begin{array}{c}\text { Molar } \\
\text { monolethic }\end{array}$} & monolethic & 46 & 40.6381 & 28.729164 & 4.235884 & 1.554 & .124 & \\
\cline { 2 - 10 } & & 25.5807 & 241397 & 14.22982 & & 23.88945 & 6.429 & $001^{*}$ \\
\hline
\end{tabular}

\section{Results of Fracture Resistance.}

The monolithic zirconia group recorded higher fracture resistance load than veneered zirconia (Table 3). The difference between both groups was statistically significant as indicated by independent t-test .The fracture mode for the monolithic bridge specimens was a bulk fracture at the connector area between the two pontics. Whereas veneered bilayer bridge specimens exhibited mixed cohesive failure of the frame-works and layering materials. Complete fracture of bilayered group (fracture of both the layering material and the zirconia coping) occurred also at the connector area between the two pontics.

TABLE (3) Descriptive statistics of fracture resistance results for both experimental groups

\begin{tabular}{|l|l|}
\hline Variables & Mean \pm SD \\
\hline Veneerd Zircon gp & $1273.407 \pm 177.601$ \\
\hline Monolithic Zircon gp & $1743.487 \pm 283.1456$ \\
\hline $\mathrm{t}$ & 2.641 \\
\hline $\mathrm{p}$ & $0.0247^{*}$ \\
\hline
\end{tabular}

\section{DISCUSSION}

The results of the current investigation revealed a significant increase in marginal gap of crowns after porcelain veneer firing. These results support the null hypothesis.

In the present study, the measurements of the marginal gap were performed on each single abutment and the specimens were not cemented to prevent variability due to luting agent type, viscosity, and seating forces during cementation and determine the exact factors that lead to the significant difference in measurement.

Various methods have been employed to evaluate the marginal fit of restorations in the literature ${ }^{[15-18]}$. Two most common nondestructive methods which permit assessment of marginal discrepancy at different fabrication stages of the restoration, are direct microscopic view and replica techniques ${ }^{[28]}$. In the current investigation direct microscopic view was used to evaluate the marginal gap of each abutment, margin restorations at detected points ${ }^{[5]} \mathrm{In}$ this technique in spite of replica technique, marginal gap could be measured in numerous points. Besides, the use of intermediate media such as impression 
material is not needed in the direct microscopic view which can limit the effect of material flaws used in the replica technique on the measurement of the $\mathrm{fit}^{[33]}$

Although in the direct microscopic view the horizontal marginal fit could not be assessed. The exposure of cement in the margin is mostly affected by the vertical marginal discrepancy, while horizontal marginal discrepancy is more critical for plaque control and maintainability of the restoration $^{[34]}$.

In the present study a holding device was used to standardize the seating of the specimens on the die during measurements. The device has the essential requirements for a standard holding device firstly was proposed by Ushiwata and de Moraes ${ }^{[35]}$. To standardize the seating of the restorations before and after veneering on the die, the morphology of occlusal surface was kept the same and accommodated to the holding device tip.

There are large variations regarding the amount of acceptable marginal gap of crown in the literature. Christensen et al. ${ }^{[36]}$ reported the range of 34$119 \mu \mathrm{m}$ for subgingival acceptable marginal gap, and 2-15 $\mu \mathrm{m}$ for supragingival margins. However, Mclean and von Fraunhofer evaluated many restorations within 5 years, and proposed $120 \mu \mathrm{m}$ as the maximum clinically acceptable marginal gap ${ }^{[1]}$ However the most acceptable marginal gap range is between 50 to $100 \mu \mathrm{m}$ for CAD/CAM restorations $^{[12]}$.In the current study, the mean marginal gap was $25 \mu \mathrm{m}$ for zirconia copings in molar restoration , $51 \mu \mathrm{m}$ for crowns which were veneered by using layering technique. Regarding the previous mentioned studies, the amount of marginal gap for all groups was within the clinically acceptable range. To number the reported marginal opening for zirconia CAD/CAM restorations in former studies; Miura et al. reported the mean marginal gap of cercon zirconia CAM crowns restorations with three different cervical finish lines designs to be $24-30 \mu \mathrm{m}^{[31]}$.
Euán et al. ${ }^{[37]}$ reviled that minimum marginal gap of the Lava zirconia copings with round shoulder margin was $52.66 \mu \mathrm{m}$. The mean marginal gap of the Procera zirconia crown was reported to be $44.2 \mu \mathrm{m}$, in Kokubo et al.'s study[38]. Some incompatible results of the current study and other researches may be related to the measuring methods and possible errors in microscopic evaluation of the marginal gap, different CAD/CAM systems which are used and the criteria which is used for the marginal gap evaluation (horizontal, vertical or absolute marginal discrepancy).

In the current investigation, using of layering, technique for veneering of zirconia copings increased the marginal gap of the restorations. In comparison, Pak et al.[26] demonstrated an increase in the marginal gap of Digident and lava CAD/CAM zirconia ceramics after veneering process. Also, the marginal fit of three all-ceramic crown systems (conventional In-ceram, copy milled In ceram, and copy-milled feldspathic crowns) in Balkaya et al.' ${ }^{[15}$ ${ }^{1}$ study changed during porcelain firing cycles. They reported that only glaze firing had no consequence on the marginal accuracy.

Alterations of the marginal fit during veneering process could be discussed by some causes. A probable reason is the shrinkage of veneering porcelain during sintering process. This shrinkage may lead to changes in the gap, due to the ceramic lifting from the margin of the $\mathrm{die}^{[41]}$. Another reason for marginal distortion during porcelain veneering process is thermal incompatibility between framework and veneering porcelain ${ }^{[15]}$. Different coefficients of thermal expansion (CTE) of coping and veneer in the layered restoration causes stress formation when the restoration cools from glass transition to room temperature ${ }^{[42]}$. One of the drawbacks of this event is deformation of the restoration. In metal ceramic restorations, a small positive mismatch in CTE enhances the strength of the restoration by applying compressive forces on 
the veneering ceramic.43 However, according to Aboushelib et al.' ${ }^{[44]}$. Study for all ceramic zirconia layered restorations, minimizing the thermal mismatch would be desirable. According to Isgro et al., ${ }^{[4]}$. even a zero thermal mismatch does not guarantee the compatibility between ceramic core and veneering porcelain so that the fast cooling procedure, viscoelastic behavior of the porcelain, and repeated firing can lead to distortion. Previous studies revealed that during repeated firing cycles, CTE of core, and veneer ceramic can change, producing a non-reliable thermal mismatch ${ }^{[46,47]}$.

\section{Fractured resistance}

It has been implied that stress intensity in the prosthesis is proportional to the length of the bridge [48]. Therefore, long restorations are expected to experience higher tensile stresses which are further destructive for ceramics specially when used in high stress areas such as posterior area. That is why the present study focused in long span (four-unit) posterior bridges.

The special, time-dependent behavior of zirconia restorations after placed in situ makes it necessary to simulate the effect of aging in the present study by thermocycling as the continuous alternations of mouth temperature caused by breathing as well as cold and hot food leads to tensions in the material mass and subcritical crack [49]. Previous studies that evaluated the clinical performance of zirconia-based restorations demonstrated that fracture of the veneering ceramic was the most frequent clinical problem with zirconia restorations for both tooth-based and implant-based restorations [50,51]. It was concluded that the veneering porcelain is the weakest link, and improving its strength could reduce the incidence of veneering porcelain chipping ${ }^{[52]}$.

Various approaches have been introduced to overcome chipping of zirconia-based restorations, including application of monolithic zirconia restorations ${ }^{[53]}$. Monolithic zirconia prostheses have been proposed A study 'analyzing the fracture loads of all-ceramic monolithic crowns' also indicated a superior performance for the monolithic design. Even though the monolithic system was made of lithium disilicate, better results were obtained when compared to bilayered zirconia ${ }^{[54]}$.

Several authors investigated fracture loads zirconia-based molar restorations fabricated with different restorative materials and designs. Four groups of zirconia-based molar restorations were tested; porcelain-layered zirconia-based restorations, indirect composite-layered zirconia-based restorations, metal-ceramic restorations, and monolithic zirconia restorations. It was found that fracture loads were significantly higher for monolithic zirconia restorations than for bilayered restorations ${ }^{[55]}$.

In the present study, the fracture resistance test showed that the mode of fracture in monolithic group represented a bulk fracture at the connector area between the two pontics. In bilayered group, complete fracture (fracture of the veneering layer and the zirconia core) also occurred in the connector area between the two pontics. Investigations using finite element analysis showed that maximum tensile stresses are concentrated in the connector area ${ }^{[56]}$. Both in-vitro and in-vivo studies demonstrated that fracture of the connectors was the exclusive mode

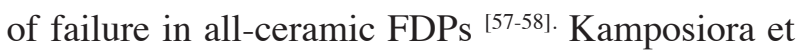
al. ${ }^{[48]}$ explained the phenomenon as follows: thin and irregularly shaped parts of the framework, such as the connector area, reach critical strain earlier than thicker parts, such as the pontics and the abutments, while loading. Thus, FDPs are expected to fail in these more easily bending areas. Therefore, connector dimensions are crucial for fracture resistance ${ }^{[59]}$.

One of the limitations of the current study is that, the specimens were produced and tested under the ideal conditions, which may not reflect the actual clinical conditions. even if the study performed 
under artificial aging condition .Another limitation is that only vertical marginal gap was measured and horizontal discrepancy was not examined. Since the measurement of internal gap necessitate the cementation and sectioning of specimens, in this study, unlike the marginal gap, the internal gap was not measured.

\section{CONCLUSION}

Within the limitations of this study, following conclusions are drawn:

The veneering tested in the current investigation altered the marginal fit of zirconia coping.and revealed clinically acceptable marginal fit.

Monolithic zirconia FDPs are well-suited for clinical use in areas of high stress and long span restorations compared to bilayered FDPs.

\section{REFERENCES}

1. Sadowsky SJ. An overview of treatment considerations for esthetic restorations: a review of the literature. J Prosthet Dent. 2006;96:433-442.

2. Liu PR. A panorama of dental CAD/CAM restorative systems. Compend Contin Educ Dent. 2005;26:507-508.

3. Miyazaki T, Hotta Y, Kunii J, Kuriyama S, Tamaki Y. A review of dental CAD/CAM: current status and future perspectives from 20 years of experience. Dent Mater J. 2009;28:44-56.

4. Bachhav VC, Aras MA. Zirconia-based fixed partial dentures: a clinical review. Quintessence Int. 2011;42:173-182.

5. Contrepois M, Soenen A, Bartala M, Laviole O. Marginal adaptation of ceramic crowns: a systematic review. J Prosthet Dent. 2013;110:447-454.

6. Jacobs MS, Windeler AS. An investigation of dental luting cement solubility as a function of the marginal gap. J Prosthet Dent. 1991;65:436-442.

7. Björn AL, Björn H, Grkovic B. Marginal fit of restorations and its relation to periodontal bone level. II. Crowns. Odontol Revy. 1970;21:337-346.

8. Schwartz NL, Whitsett LD, Berry TG, Stewart JL. Unserviceable crowns and fixed partial dentures: life-span and causes for loss of serviceability. J Am Dent Assoc. 1970;81:1395-1401.

9. Bergenholtz G, Cox CF, Loesche WJ, Syed SA. Bacterial leakage around dental restorations: its effect on the dental pulp. J Oral Pathol. 1982;11:439-450.

10. Heintze SD. Systematic reviews: I. The correlation between laboratory tests on marginal quality and bond strength. II. The correlation between marginal quality and clinical outcome. J Adhes Dent. 2007;9:77-106.

11. McLean JW, von Fraunhofer JA. The estimation of cement film thickness by an in vivo technique. Br Dent J. 1971;131:107-111

12. Euán R, Figueras-Álvarez O, Cabratosa-Termes J, OliverParra R. Marginal adaptation of zirconium dioxide copings: influence of the CAD/CAM system and the finish line design. J Prosthet Dent. 2014;112:155-162.

13. Holmes JR, Sulik WD, Holland GA, Bayne SC. Marginal fit of castable ceramic crowns. J Prosthet Dent. 1992;67:594599.

14. Holmes JR, Bayne SC, Holland GA, Sulik WD. Considerations in measurement of marginal fit. J Prosthet Dent. 1989;62:405-408.

15. Balkaya MC, Cinar A, Pamuk S. Influence of firing cycles on the margin distortion of 3 all-ceramic crown systems. J Prosthet Dent. 2005;93:346-355.

16. Luthardt RG, Bornemann G, Lemelson S, Walter MH, Hüls A. An innovative method for evaluation of the 3-D internal fit of CAD/CAM crowns fabricated after direct optical versus indirect laser scan digitizing. Int $\mathrm{J}$ Prosthodont. 2004;17:680-685.

17. Pelekanos S, Koumanou M, Koutayas SO, Zinelis S, Eliades G. Micro-CT evaluation of the marginal fit of different In-Ceram alumina copings. Eur J Esthet Dent. 2009;4:278-292.

18. Sorensen JA. A standardized method for determination of crown margin fidelity. J Prosthet Dent. 1990;64:18-24.

19. Kanat B, Cömlekoğlu EM, Dündar-Çömlekoğlu M, Hakan Sen B, Ozcan M, Ali Güngör M. Effect of various veneering techniques on mechanical strength of computercontrolled zirconia framework designs. J Prosthodont. 2014;23:445-455.

20. Wimmer T, Erdelt KJ, Eichberger M, Roos M, Edelhoff D, Stawarczyk B. Influence of abutment model materials 
on the fracture loads of three-unit fixed dental prostheses. Dent Mater J. 2014;33:717-724.

21. Tsalouchou E, Cattell MJ, Knowles JC, Pittayachawan P, McDonald A. Fatigue and fracture properties of yttria partially stabilized zirconia crown systems. Dent Mater. 2008;24:308-318.

22. Beuer F, Schweiger J, Eichberger M, Kappert HF, Gernet W, Edelhoff D. High-strength CAD/CAM-fabricated veneering material sintered to zirconia copings-a new fabrication mode for all-ceramic restorations. Dent Mater. 2009;25:121-128.

23. Pera P, Gilodi S, Bassi F, Carossa S. In vitro marginal adaptation of alumina porcelain ceramic crowns. J Prosthet Dent. 1994;72:585-590.

24. Shearer B, Gough MB, Setchell DJ. Influence of marginal configuration and porcelain addition on the fit of In-Ceram crowns. Biomaterials. 1996;17:1891-1895.

25. Castellani D, Baccetti T, Clauser C, Bernardini UD. Thermal distortion of different materials in crown construction. J Prosthet Dent. 1994;72:360-366.

26. Pak HS, Han JS, Lee JB, Kim SH, Yang JH. Influence of porcelain veneering on the marginal fit of Digident and Lava CAD/CAM zirconia ceramic crowns. J Adv Prosthodont. 2010;2:33-38. 27. Fahmy NZ. Influence of veneering materials on the marginal fit and fracture resistance of an alumina core system. J Prosthodont. 2011;20:45-51.

28. Kohorst P, Brinkmann H, Dittmer MP, Borchers L, Stiesch M. Influence of the veneering process on the marginal fit of zirconia fixed dental prostheses. J Oral Rehabil. 2010;37:283-291

29. Sulaiman F, Chai J, Jameson LM, Wozniak WT. A comparison of the marginal fit of In-Ceram, IPS Empress, and Procera crowns. Int J Prosthodont. 1997;10:478-484.

30. Cho SH, Nagy WW, Goodman JT, Solomon E, Koike M. The effect of multiple firings on the marginal integrity of pressable ceramic single crowns. J Prosthet Dent. 2012;107:17-23.

31. Miura S, Inagaki R, Kasahara S, Yoda M. Fit of zirconia allceramic crowns with different cervical margin designs, before and after porcelain firing and glazing. Dent Mater J. 2014;33:484-489.

32. Rosensteil SF, Land MF, Fujimoto J. Contemporary fixed prosthodontics. Tooth preparation for All-ceramic restorations. 4th ed. St. Louis: Elsevier; 2006. p. 326.
33. Alghazzawi TF, Liu PR, Essig ME. The effect of different fabrication steps on the marginal adaptation of two types of glass-infiltrated ceramic crown copings fabricated by CAD/CAM technology. J Prosthodont. 2012;21:167-172.

34. Sorensen JA. A standardized method for determination of crown margin fidelity. J Prosthet Dent. 1990;64:18-24

35. Ushiwata O, de Moraes JV. Method for marginal measurements of restorations: accessory device for toolmakers microscope. J Prosthet Dent. 2000;83:362-366.

36. Christensen GJ. Marginal fit of gold inlay castings. J Prosthet Dent. 1966;16:297-305.

37. Euán R, Figueras-Álvarez O, Cabratosa-Termes J, Brufau-de Barberà M, Gomes-Azevedo S. Comparison of the marginal adaptation of zirconium dioxide crowns in preparations with two different finish lines. J Prosthodont. 2012;21:291-295.

38. Kokubo Y, Ohkubo C, Tsumita M, Miyashita A, Vult von Steyern P, Fukushima S. Clinical marginal and internal gaps of Procera AllCeram crowns. J Oral Rehabil. 2005;32:526-530.

39. Lee KB, Park CW, Kim KH, Kwon TY. Marginal and internal fit of all-ceramic crowns fabricated with two different CAD/CAM systems. Dent Mater J. 2008;27:422-426.

40. Bhowmik H, Parkhedkar R. A comparison of marginal fit of glass infiltrated alumina copings fabricated using two different techniques and the effect of firing cycles over them. J Adv Prosthodont. 2011;3:196-203.

41. Weaver JD, Johnson GH, Bales DJ. Marginal adaptation of castable ceramic crowns. J Prosthet Dent. 1991;66:747753.

42. DeHoff PH, Barrett AA, Lee RB, Anusavice KJ. Thermal compatibility of dental ceramic systems using cylindrical and spherical geometries. Dent Mater. 2008;24:744-752.

43. Nielsen JP, Tuccillo JJ. Calculation of interfacial stress in dental porcelain bonded to gold alloy substrate. J Dent Res. 1972;51:1043-1047.

44. Aboushelib MN, Feilzer AJ, de Jager N, Kleverlaan CJ. Prestresses in bilayered all-ceramic restorations. J Biomed Mater Res B Appl Biomater. 2008;87:139-145.

45. Isgrò G, Wang H, Kleverlaan CJ, Feilzer AJ. The effects of thermal mismatch and fabrication procedures on the deflection of layered all-ceramic discs. Dent Mater. 2005;21:649-655. 
46. Fairhurst CW, Anusavice KJ, Hashinger DT, Ringle RD, Twiggs SW. Thermal expansion of dental alloys and porcelains. J Biomed Mater Res. 1980;14:435-446.

47. Isgrò G, Kleverlaan CJ, Wang H, Feilzer AJ. Thermal dimensional behavior of dental ceramics. Biomaterials. 2004;25:2447-2453.

48- Kamposiora P, Papavasiliou G, Bayne SC. Stress concentration in all-ceramic posterior fixed partial dentures. Quint Int 1996; 27:701-706.

49- Swab JJ. Low temperature degradation of Y-TZP materials. J Mater Sci 1991; 26: 6706-6714.

50- Örtorp A, Kihl ML, Carlsson GE. A 5-year retrospective study of survival of zirconia single crowns fitted in a private clinical setting. J Dent 2012; 40:527-530.

51- Ashkanani HM, Raigrodski AJ, Flinn BD, Heindl H, Mancl LA. Flexural and shear strengths of $\mathrm{ZrO} 2$ and high-noble alloy bonded to their corresponding porcelains. J Prosthet Dent 2008; 100:274-284.

52- Rinke S, Fischer C. Range of indications for translucent zirconia modifications: clinical and technical aspects. Quint Int 2013; 44:557-566.

53- Zhang Y, Lee J, Srikanth R, Lawn BR. Edge chipping and flexural resistance of monolithic ceramics. Dent Mater 2013; 29:1201-1208.

54- Kim JH, Lee SJ, Park JS, Ryu JJ. Fracture load of monolithic CAD/CAM lithium disilicate ceramic crowns and veneered zirconia crowns as a posterior implant restoration. Impla Dent 2013; 22:66-70.

55- Weiser PF, Handel G, Rosentritt M. Wear performance of monolithic dental ceramics with different surface treatments. Quint Int 2013; 44:393-405.

56- Matsuzaki F, Sekine H, Honma SH, Takanashi T, Furuya K, Yajima Y,et al. Translucency and flexural strength of monolithic translucent zirconia and porcelain-layered zirconia, Den Mat J 2015; 34:910-917.

57- Silva N, Thompson VP, Valverde GB. Comparative reliability analyses of zirconium oxide and lithium disilicate restorations in vitro and in vivo. J Am Dent Assoc 2011; 142:4-9.

58-Aboushelib MN, Kleverlaan CJ, Feilzer AJ. Effect of zirconia type on its bond strength with different veneer ceramics. J Prosthodont 2008; 17:401-408.

59- Lameira DP, Silva WA, Silva FA, De Souza GM. Fracture strength of aged monolithic and bi-layer zirconia-based crowns. Bio Med Res Int 2015: 41:41-86. 